\title{
ESPECIALIZAÇÃO EM EDUCAÇÃO PROFISSIONAL TÉCNICA DE NÍVEL MÉDIO DO IFPR - CAMPUS CURITIBA: UMA CONTRIBUIÇÃO PARA A EDUCAÇÃO E TRABALHO NA PÓS- GRADUAÇÃO BRASILEIRA
}

\author{
Wilson Lemos Junior*; Leandro Rafael Pinto \\ E-mail*: wilson.lemos@ifpr.edu.br \\ Instituto Federal de Educação, Ciência e Tecnologia do Paraná \\ DOI: 10.15628/rbept.2018.11194
}

Artigo submetido em: set/2020 e aceito em: dez/2020

\begin{abstract}
RESUMO
O Instituto Federal do Paraná é uma instituição voltada para a formação em educação profissional e tecnológica, porém a capacitação de professores é uma preocupação constante. No final de 2013, o Campus Curitiba aprovou o curso lato sensu em Educação Profissional Técnica de Nível Médio, em prol de auxiliar na capacitação de professores que atuam ou desejam atuar na área. Este artigo tem por objetivo apresentar um relato de experiência desta especialização nos primeiros seis anos de funcionamento do curso (2014 a 2019). Por meio de pesquisa documental e análise de conteúdo, o estudou se debruçou sobre: i) organização do curso, por meio de estudo de seu Projeto Pedagógico; ii) análise das temáticas desenvolvidas nos TCC entre 2014 a 2019. Como resultados temos: a) o curso se organizou de modo a contemplar diversas temáticas relacionadas a educação profissional e tecnológica de nível médio; b) o curso passou por modificações do corpo docente, devido principalmente aos afastamentos, remoções e entrada de servidores no Campus; c) a especialização está na sua sexta turma, ao todo já certificou um total de 84 especialistas; d) as temáticas mais pesquisadas em seus TCC são conhecimentos técnicos, histórico de cursos e instituições de ensino, egressos, mundo do trabalho, prática docente, organização curricular e temas específicos relacionados com a educação profissional técnica. Por fim, destaca-se que o curso vem cumprindo seu papel no instituto, sendo uma especialização já consolidada no cenário educacional da região.
\end{abstract}

Palavras-Chave: Formação de professores. Educação Profissional, Técnica e Tecnológica. Pós-graduação lato sensu.

\section{SPECIALIZATION IN VOCATIONAL-TECHNICAL HIGH SCHOOL EDUCATION AT IFPR - CURITIBA CAMPUS: A CONTRIBUTION TO EDUCATION AND WORK IN BRAZILIAN POST-GRADUATE}

\begin{abstract}
The Federal Institute of Paraná is an institution focused on vocational and technological education. Therefore, teachers' training has been a constant concern. At the end of 2013, Campus Curitiba's Head Department approved the Post-graduate program lato sensu (specialist category) in Vocational-Technical High School, in order to assist in the training of teachers who work or wish to work in the area. This article aims to present an experience report of the the first six years of the Program. Through documentary research and content analysis, the study focused on: i) organization of the Program through the study of its Pedagogical Project; ii) analysis of the themes developed in the end-of-course written papers between 2014
\end{abstract}


and 2019. The outcomes were: a) the Program has been organized in order to approach several themes related to vocational-technical high school education; $b$ ) it underwent changes in the teaching staff, mainly Due to the dynamics imposed by study leaves taken by our professors and the consequent hiring of new ones; $c$ ) the specialization is in its sixth class, and it has already certified a total of 84 professionals; d) the most researched subjects in the end-ofcourses written papers are technical knowledge, history of vocational and technical high school and teaching institutions; graduates, the world of work, teaching practice and specific topics related to vocational -technical education. Finally, it is paramount to add that the Program has been fulfilling its role at the Institute, for it is already consolidated in the educational scenario of the region.

Keywords: Teachers' training. Vocational-technical high school. Post-graduate program lato sensu (specialist category).

\section{INTRODUÇÃO}

O IFPR (instituto Federal de Educação, Ciência e Tecnologia do Paraná) foi criado no ano de 2008, pela Lei n. .11 .892 de 29 de dezembro. Juntamente com o IFPR, foram criados 38 Institutos Federais - IFs, em grande maioria, a partir das transformações de Centro Federais de Educação Tecnológica ou Integração entre Centros Federais de Educação Tecnologia (CEFETs), Escolas Técnicas e Agrotécnicas Federais (EAFs). Os Institutos Federais constituíram-se de 38 EAFs, 32 CEFETs, 8 Escolas Técnicas Federais e 8 Escolas Técnicas Vinculadas, perfazendo um total de 86 escolas, muitas delas herdeiras das primeiras Escolas de Aprendizes e Artífices, criadas em 1909 por meio do Decreto 7566, de 23 de setembro. Os IFs incorporavam a tradição do ensino técnico brasileiro. (ORTIGARA; GANZELI, 2013).

Desde sua criação, a proposta dos IFs se mostrou como inovadora, conforme relatado por Pacheco (2010, p.13):

O governo federal, por meio do Ministério da Educação, criou um modelo institucional absolutamente inovador em termos de proposta ecnológ-pedagógica: os Institutos Federais de Educação, Ciência e Tecnologia. Essas instituições têm suas bases em um conceito de educação profissional e ecnológica sem similar em nenhum outro país. São 38 institutos, com 400 campi espalhados por todo o território brasileiro, além de várias unidades avançadas, atuando em cursos técnicos (50\% das vagas), em sua maioria na forma integrada com o ensino médio, licenciaturas (20\% das vagas) e graduações tecnológicas, podendo ainda disponibilizar especializações, mestrados profissionais e doutorados ecnológ principalmente para a pesquisa aplicada de inovação ecnológica. 
Percebe-se que a formação de professores era uma das preocupações dos Ifs. Além disso, destaca-se a característica da verticalidade dos cursos, abrangendo desde cursos técnicos de nível médio até o doutorado:

\begin{abstract}
A organização pedagógica verticalizada, da educação básica à superior, é um dos fundamentos dos Institutos Federais. Ela permite que os docentes atuem em diferentes níveis de ensino e que os discentes compartilhem espaços de aprendizagem, incluindo os laboratórios, possibilitando 0 delineamento de trajetórias de formação que podem ir do curso técnico ao doutorado. A estrutura multicampi e a clara definição do território de abrangência das ações dos Institutos Federais afirmam, na missão dessas instituições, o compromisso de intervenção em suas respectivas regiões, identificando problemas e criando soluções técnicas e tecnológicas para o desenvolvimento sustentável com inclusão social. (PACHECO, 2015, p.13).
\end{abstract}

No final de 2013, o IFPR - Campus Curitiba aprovou o curso lato sensu em Educação Profissional Técnica de Nível Médio, em prol de auxiliar na capacitação de professores que atuam ou desejam atuar na área. Este artigo tem por objetivo apresentar um relato de experiência desta Especialização nos primeiros 6 (seis) anos de funcionamento do curso, no qual ingressaram ao todo 6 (seis) diferentes turmas, uma em cada ano a partir de 2014.

Por meio de pesquisa documental e análise de conteúdo, o estudo se debruçou sobre: i) organização do curso, por meio de estudo de seu Projeto Pedagógico Curricular; ii) análise das temáticas desenvolvidas nos Trabalhos de Conclusão de Curso (TCC) entre os anos de 2014 a 2019.

Sendo assim, o artigo encontra-se dividido em duas partes, sendo a primeira parte dedicada a organização da Especialização em Educação Profissional Técnica de Nível Médio do IFPR - Campus Curitiba, no qual serão analisados o Projeto Pedagógico do Curo (PPC) e os editais de ingresso. A segunda parte, trata da análise das temáticas desenvolvidas nos TCC entre os anos de 2014 a 2019. As análises do período de 2014 a 2019, envolvem 4 (quatro) turmas que, em sua grande maioria, já finalizaram o curso. As turmas ingressantes em 2018 e 2019 não foram analisadas por encontrarem-se atualmente no meio de eu itinerário formativo.

\title{
2 A ORGANIZAÇÃO DA ESPECIALIZAÇÃO EM EDUCAÇÃO PROFISSIONAL TÉCNICA DE NÍVEL MÉDIO DO IFPR - CAMPUS CURITIBA
}

Neste item, objetiva-se relatar o processo de criação do curso de Especialização em Educação Profissional Técnica de Nível Médio ofertado no IFPR - Campus Curitiba. A produção do projeto pedagógico do curso (PPC) foi iniciado no ano de 2013, contando com a participação de alguns professores Vol. 2 (2020) 
do IFPR - Campus Curitiba. Inicialmente, o curso foi elaborado em 2013 por professoras do curso técnico de Secretariado do IFPR - Campus Curitiba: as docentes Diana Gurgel Pegorini, Tatiani Daiana de Novaes e Caterine Pereira Moraz. Nesse mesmo ano, somou-se a colaboração do professor Wilson Lemos Junior.

O PPC foi aprovado e autorizado pela Resolução n.․ 38 , de 9 de dezembro de 2013. O curso de Especialização em Educação Profissional Técnica de Nível Médio foi o primeiro curso da modalidade em forma presencial a ser autorizado pelo IFPR. De acordo com PPC da Especialização em Educação Profissional:

\begin{abstract}
O ensino profissional vem sendo ampliado em todo contexto nacional, no entanto, não há no território nacional, uma grande quantidade de cursos de formação de professores voltados para essa realidade. Nessa perspectiva, o Instituto Federal do Paraná, envolvido com as questões educacionais nacionais e regionais, e sentindo-se responsável pela formação de uma parcela da população destinada ao exercício profissional de gestão educacional, propõe esse curso. Assim, a proposta da especialização objetiva oferecer um ensino de qualidade, em sintonia com as novas concepções, conhecimentos e inovações desse campo educacional, considerando os avanços tecnológicos necessários para atuação do docente nessa modalidade de ensino. (IFPR, 2015, p. 9).
\end{abstract}

A formação e capacitação de professores sempre foi uma das preocupações centrais dos institutos federais. Evidentemente, um curso de especialização não tem como objetivo substituir a licenciatura, mas ainda assim pode ser de grande valia para a formação docente por ofertar uma série de componentes curriculares que abordam temáticas pedagógicas. O público alvo da Especialização em Educação Profissional do IFPR:

[...] é o profissional com formação superior, licenciado ou não, preferencialmente que atue como docente em cursos de formação técnica e tecnológica. Pretende-se com essa formação que este curso possa contribuir para o desenvolvimento social do profissional e no próprio processo de crescimento intelectual dos indivíduos. (IFPR, 2015, p.14).

De acordo com o estabelecido no PPC do curso, os principais objetivos da Especialização são: 
Capacitar os profissionais que atuam na Educação Profissional Técnica de Nível Médio promovendo uma formação articulada à realidade do mundo do trabalho, à ação pedagógica e à base tecnológica de sua área de conhecimento, com vistas a desenvolver uma educação de qualidade, com capacidade para atuar na elaboração de estratégias, no estabelecimento de formas criativas das atividades de ensino e aprendizagem e de prever pró-ativamente as condições necessárias e as alternativas possíveis para o desenvolvimento adequado da Especialização em Educação Profissional Técnica de nível médio, considerando as peculiaridades, as circunstâncias particulares e as situações contextuais concretas.

Objetivos específicos 1. Formar e qualificar profissionais especialistas para atuar na Educação profissional como docente; 2. Aprimorar o desempenho profissional dos professores que atuam na Educação profissional; 3. Ampliar a pesquisa referente à Educação Profissional e divulgá-la dentro dos princípios que norteiam a especialização no IFPR, produzindo conhecimentos como síntese da formulação e implementação teórico-prática; 4. Promover uma formação docente voltada à realidade da Educação Profissional Técnica em nível médio, a partir de fundamentos teóricos e práticos da educação voltados para a especificidade dessa modalidade educacional; 5. Formar um profissional capaz de atuar na modalidade da Educação Profissional Técnica em nível médio de forma autônoma, crítica e propositiva frente aos problemas educacionais (IFPR, 2015, p.12).

Os objetivos do curso evidenciam uma formação crítica e autônoma para os professores da educação profissional:

No seu exercício o professor da EPT deve ser capaz de permitir que seus alunos compreendam, de forma reflexiva e crítica, os mundos do trabalho, dos objetos e dos sistemas tecnológicos dentro dos quais estes evoluem; as motivações e interferências das organizações sociais pelas quais e para as quais estes objetos e sistemas foram criados e existem; a evolução do mundo natural e social do ponto de vista das relações humanas com o progresso tecnológico; como os produtos e processos tecnológicos são concebidos, fabricados e como podem ser utilizados; métodos de trabalho dos ambientes tecnológicos e das organizações de trabalho. (MALDANER, p. 188, 2017) . 
Moura (2008, p.30) complementa que: (2008):

A formação e a capacitação devem, portanto, ir além da aquisição de técnicas didáticas de transmissão de conteúdos para os professores e de técnicas de gestão para os dirigentes. Evidentemente, esses aspectos continuarão sendo importantes, mas o objetivo macro é mais ambicioso e deve privilegiar a formação no âmbito das políticas públicas do país, principalmente as educacionais, numa perspectiva de superação do modelo de desenvolvimento socioeconômico vigente, de modo que se deve priorizar mais o ser humano do que, simplesmente, as relações de mercado e o fortalecimento da economia. (MOURA, p.30, 2008).

Desde sua primeira turma, o curso ocorre presencialmente aos sábados tanto no período matutino quanto no vespertino. O horário das aulas é das 8:00 às 12:00, retornando no período da tarde das $13: 00$ até às 18:00 horas. Foi o primeiro curso a utilizar os sábados para ofertar um ensino regular no IFPR Campus Curitiba. Cada disciplina do curso é ministrada em 3 (três) sábados consecutivos, totalizando 30 horas para cada componente curricular.

Em relação aos processos avaliativos propostos da Especialização em Educação Profissional Técnica de Nível Médio do IFPR, o PPC orienta que estes ocorram por meio de:

[...] seminários, trabalhos individuais ou em grupos, testes escritos e orais, dramatizações, demonstrações de técnicas em laboratórios, apresentação de trabalhos finais de iniciação científica; artigos científicos, trabalho final de curso, portfólios, resenhas, autoavaliação, entre outros. Cada disciplina deverá propor no mínimo duas avaliações e recomenda-se que nos momentos em que elas ocorram, o(a) professor(a) faça uso de formas e meios diferenciados para contemplar as múltiplas inteligências $e$ as habilidades dos alunos na modalidade presencial. Fica vedado ao professor submeter o aluno a uma única oportunidade e a um único instrumento de avaliação. Os resultados das avaliações serão expressos em conceitos A, B, $C$ ou D. Será considerado aprovado o aluno que obtiver os conceitos $\mathrm{A}, \mathrm{B}$ ou $\mathrm{C}$ e frequência igual ou superior a $75 \%$ (setenta e cinco por cento) na unidade/área curricular. Caso o aluno seja reprovado por conceito ele terá a oportunidade de realizar uma avaliação final. Caberá ao professor de cada disciplina elaborar tal avaliação. (IFPR, 2015, p.55). 
No ano de 2015, os cursos de Especializações receberam nova regulamentação do governo federal. Com isso, a Reitoria do IFPR acabou solicitando adaptações para o PPC do curso para se adequar à nova legislação, além da inclusão de alguns tópicos que até então não constavam na primeira versão do texto.

A primeira coordenação da Especialização em Educação Profissional, no biênio de 2013 a 2015, foi formada pelas professoras Diana Gurgel Pegorini na coordenação e Tatiani Daiana de Novaes como vice. Entre os anos de 2016 e 2017, o professor Wilson Lemos Junior coordenou o curso juntamente com a professora Sandra Terezinha Urbanetz na vice coordenação. No início de 2018, a professora Érika Pessanha d'Oliveira assumiu a coordenação do curso, juntamente com a professora Rosangela Gonçalves de Oliveira como vice, equipe que se mantém até hoje.

De acordo com o edital 01/2014, a primeira turma que ingressou por meio de processo seletivo ocorreu no ano de 2014. O processo seletivo contou com 3 (três) formas de avaliação sendo: 40 (quarenta) pontos destinados ao currículo, 40 (pontos) para entrevista e 20 (vinte) pontos para carta de intenção. Foram 56 inscritos para um total de 40 vagas. Em conversa entre a Coordenação e o Colegiado formado pelos professores que atuariam no curso, ficou decidido que todos os estudantes que estiveram presentes nas etapas do processo seletivo seriam aprovados. O curso iniciou com 47 (quarenta e sete) estudantes matriculados.

De acordo com o edital 17/2014, a seleção da segunda turma foi realizada no final de 2014 objetivando o ingresso da nova turma para o ano letivo de 2015. Foi incluída a análise de currículo no valor de 30 pontos no qual era contabilizado apenas o tempo de docência, considerando 0,5 ponto para cada ano de docência e mais 0,5 ano para cada ano de experiência na educação profissional. Além disso, os estudantes deviam realizar uma avaliação no valor de 70 (setenta) pontos respondendo as seguintes questões: Porque você escolheu essa pós-graduação? Como você aplicará os conhecimentos adquiridos na sua profissão? Que importância você acha que a educação profissional tem no desenvolvimento regional? Qual a contribuição que você espera dar ao curso, considerando a sua formação e atuação profissional? Essas avaliações foram preenchidas presencialmente no dia 29 de novembro de 2014.

De acordo com o edital 45/2015, a terceira turma prestou o processo seletivo durante o segundo semestre de 2015 contando com 59 candidatos. Destes 47 (quarenta e sete) prestaram todas as etapas do processo seletivo. O Colegiado da Especialização em Educação Profissional novamente optou por permitir o ingresso de todos os candidatos.

A quarta turma ingressou no IFPR em fevereiro de 2017. De acordo com o edital 77/2016, o processo seletivo foi alterado sendo anotados 50 pontos para preenchimento de uma avaliação consistindo em 2 questões, sendo: 
I) Descreva sua trajetória acadêmica e profissional articulando seu interesse em cursar o curso da Especialização em Educação Profissional Técnica em Nível Médio do IFPR Campus Curitiba;

II) Indique sucintamente um possível tema de pesquisa a ser desenvolvido por você na Especialização em Educação Profissional. Apresente uma proposta de tema, assim como seus objetivos e sua justificativa para essa pesquisa.

Somou-se a este processo seletivo, a análise de currículo valendo 50 (cinquenta) pontos, mantendo até 30 (trinta) pontos referentes a formação do candidato e mais 20 (vinte) pontos relativos à experiência docente. Está foi a primeira turma no qual houve a necessidade de cortar candidatos no processo seletivo. O edital previa 30 (trinta) vagas, porém foram 76 (setenta e seis) inscritos. Foi o processo seletivo de maior concorrência da história do curso até o momento.

De acordo com o edital 20/2017, no ano de 2018, houve o ingresso da quinta turma do curso, seguindo os mesmos procedimentos do edital anterior. Neste processo seletivo, ingressaram no curso 35 (trinta e cinco) estudantes em um total de 59 (cinquenta e nove) candidatos inscritos. Assim como na turma ingressante em 2016 e 2017, houve a necessidade de seleção de candidatos. O edital previa inicialmente apenas 30 (trinta) vagas, porém, 0 colegiado decidiu por maioria simples, ofertar mais 5 (cinco) vagas adicionais naquele ano, completando uma turma de 35 (trinta e cinco) estudantes.

Por ter um número significativo de estudantes que ainda não havia defendido os seus Trabalhos de Conclusão de Curso e poucos professores no curso com disponibilidade de orientação, optou-se por não abrir o processo seletivo no final de 2018. Sendo assim, a sexta turma da especialização em Educação Profissional prestou processo seletivo apenas no 1ํㅗㄹ semestre do ano de 2019, por meio do edital 39/2019. Foi mantido os quesitos do processo seletivo do ano anterior, porém neste ano, não houve grande procura pelo curso. Foram 24 (vinte e quatro) candidatos inscritos, sendo todos aprovados no processo seletivo. Porém, como muitos não realizaram as matrículas, foi publicado o edital 35/2019 ofertando 15 (quinze) vagas remanescentes.

O curso manteve a grade de disciplinas e carga horária nas duas versões do PPC produzidas pela Comissão de Elaboração do PPC. São ao todo 12 (doze) disciplinas presenciais com carga horária de 30 horas cada e mais a disciplina de TCC, ofertada pelo orientador (não necessariamente possuind o o caráter presencial) complementando a carga horária total do curso de 390 horas. De acordo com o PPC do curso, as disciplinas presentes na Especialização em Educação Profissional Técnica de Nível Médio são: 
Quadro I: Componentes curriculares do curso de Especialização em Educação Profissional Técnica de Nível Médio

\begin{tabular}{|l|c|}
\hline \multicolumn{1}{|c|}{ Componente curricular } & Carga horária total \\
\hline Trabalho e educação & 30 horas \\
\hline História e concepções da Educação Profissional & 30 horas \\
\hline $\begin{array}{l}\text { Legislação e Políticas públicas para a educação } \\
\text { profissional }\end{array}$ & 30 horas \\
\hline Avaliação da Aprendizagem & 30 horas \\
\hline Organização e Gestão da educação profissional & 30 horas \\
\hline Ética e educação & 30 horas \\
\hline Psicologia da educação profissional & 30 horas \\
\hline Formação Docente & 30 horas \\
\hline Educação Inclusiva & 30 horas \\
\hline $\begin{array}{l}\text { Tecnologias de informação e comunicação na } \\
\text { educação }\end{array}$ & 30 horas \\
\hline Metodologia da educação profissional & 30 horas \\
\hline Metodologia Científica & 30 horas \\
\hline Trabalho de Conclusão de Curso - TCC & 30 horas \\
\hline Total da Carga horária & 390 horas \\
\hline
\end{tabular}

Fonte: PPC da Especialização em Educação Profissional do IFPR (2015)

A defesa do TCC seguiu o mesmo formato desde a primeira turma, sendo necessário para a conclusão do curso, a produção de um artigo entre 15 e 25 páginas relacionado à temática da Educação Profissional Técnica de Nível Médio, defendido perante uma banca formada por 3 (três) professores, sendo o orientador e mais 2 (dois) membros avaliadores. Na defesa, os avaliadores fazem as suas considerações, elencando conceitos avaliativos para os seguintes itens: Objetivos, Justificativa, Fundamentação Teórica e Procedimentos Metodológicos. Após as arguições, a banca chega em um conceito final, sendo de $A$ até $C$, considerado aprovado e $D$ considerado reprovado, conforme regulamento 50/2017 do IFPR. Na ata de defesa, a banca, além dos conceitos, dá um parecer entre: aprovado, aprovado com modificações ou reprovado. Quando o trabalho é aprovado com alterações solicitadas, o estudante tem um prazo de até 30 dias para realizar as devidas correções no texto. 


\section{ANÁLISE DAS TEMÁTICAS DESENVOLVIDAS NOS TRABALHOS DE CONCLUSÃO DE CURSO DA ESPECIALIZAÇÃO EM EDUCAÇÃO PROFISSIONAL TÉCNICA DE NÍVEL MÉDIO}

Neste tópico, seriam analisadas à princípio, as temáticas referentes às 5 primeiras turmas ingressantes no curso, pois a sexta turma ainda se encontra em pleno processo formativo. Porém, vários estudantes da quinta turma ainda não concluíram seus TCCs devido principalmente as limitações ligadas as questões do isolamento devido a pandemia de Covid-19, impossibilitando algumas atividades práticas ou mesmo coleta de referências e documentos. Por isso, neste estudo optou-se em analisar apenas as temáticas de TCC produzidos pelas quatro primeiras turmas.

Segundo o PPC, o Trabalho de Conclusão de Curso trata-se da "execução de uma atividade prática-pedagógica visando a elaboração um texto científico na forma de artigo ou relato de experiência, ambos desenvolvidos individualmente" (IFPR, 2015, p. 69).

Mais especificamente, o TCC poderá ser de natureza:

a) teórica, em que o aluno se debruça sobre uma temática relevante com o objetivo de rever a bibliografia produzida até então, devendo analisar conceitos de vários autores e propor ou apontar novas formulações que elucidem melhor o tema em questão; ou

b) teórico-empírica, em que o aluno elabora, juntamente com a pesquisa teórica, uma pesquisa de campo, entrando em contato direto com o universo do seu objeto de estudo e, fundamentando assim, a discussão teórica a partir da análise do material coletado. (IFPR, 2015, p. 74).

Para o segundo caso, o estudante, junto a seu orientador, poderá escolher uma instituição de ensino na qual aplicará uma atividade pedagógica. O relato de experiência consistirá na descrição da atividade pedagógica aplicada, bem como os processos de aprendizagem realizados ao longo do curso e sua aplicabilidade na atividade pedagógica desenvolvida.

Dada estas regras, desde a primeira turma do curso tinha-se como hipótese que a maioria dos estudantes desenvolveriam trabalhos teóricoempíricos, pois o perfil dos ingressantes seria na sua maioria de docentes que já atuavam ou tinham expectativa de atuar com a educação profissional técnica de nível médio. Porém, ao longo dos anos, notou-se que esta expectativa não se concretizou devido a três fatores: a) o ingresso de uma grande quantidade de estudantes que não tinham uma relação direta ou possibilidade imediata de trabalho com a educação profissional e tecnológica; b) a dificuldade em desenvolver atividades práticas em instituições de educação profissional 
devido a falta de tempo ou conciliação de horários dos estudantes da especialização ou questões éticas e legais do trabalho em sala de aula; c) a descoberta de temáticas diversas que a educação profissional possibilita, como história da educação, formação profissional, currículo, dentre outros, que acabou despertando reflexões diretas nos estudantes da especialização.

Para conhecer esta realidade, levantou-se junto a Diretoria de Registro e Acompanhamento Acadêmico (Dirac) do IFPR, os títulos e temas dos TCC desenvolvidos e certificados das 4 primeiras turmas da especialização. Chegou-se a um total de 84 (oitenta e quatro) TCC defendidos e que geraram a conclusão do curso e certificação do estudante. Lembrando que a defesa do TCC, segundo o PPC, não garante a conclusão do curso pois o estudante pode defender o trabalho mesmo tendo reprovações ou pendências em alguma disciplina e que só após resolver estas pendências é que se pode solicitar a certificação.

Levantado todos os títulos dos TCC, optou-se em agrupá-los por temáticas para melhor analisá-los. O PPC não prevê linhas de pesquisa para esta especialização, porém, em uma análise dos títulos e conteúdos nota-se que há quatro grandes áreas temáticas nas produções monográficas, todas ligadas a Educação Profissional Técnica de Nível Médio (EPTNM):

a) Práticas Educativas em EPTNM: compreende os trabalhos teóricoempíricos, que utilizaram práticas em sala de aula visando compreender ou melhorar processos de ensino e aprendizagem em diferentes componentes curriculares de cursos técnicos e profissionalizantes;

b) Gestão, Organização e Políticas da EPTNM: enquadra todos os trabalhos, teóricos ou práticos, que analisaram temas ligados a gestão escolar, organização do trabalho docente ou políticas diversas que implicam na educação profissional;

c) História e Memória da EPTNM: engloba todas as pesquisas que se debruçaram em compreender a história de uma instituição, de um curso o mesmo de uma formação profissional específica;

d) Currículo, Formação e Avaliação em EPTNM: conjunto dos trabalhos, teóricos ou práticos, que analisaram componentes curriculares específicos de alguns cursos, o percurso formativo e os processos avaliativos diversos utilizados na educação profissional.

Vale lembrar que estas categorias foram determinadas com base no conteúdo dos títulos dos TCC, sem indicação dos autores dos mesmos. Entende-se que as categorias indicadas abarcam as temáticas das 84 produções analisadas que, quantitativamente, ficam assim divididas (Gráfico 1): 
Gráfico 1: Total de TCC das 4 primeiras turmas, por linhas de pesquisa, da Especialização em Educação Profissional Técnica de Nível Médio

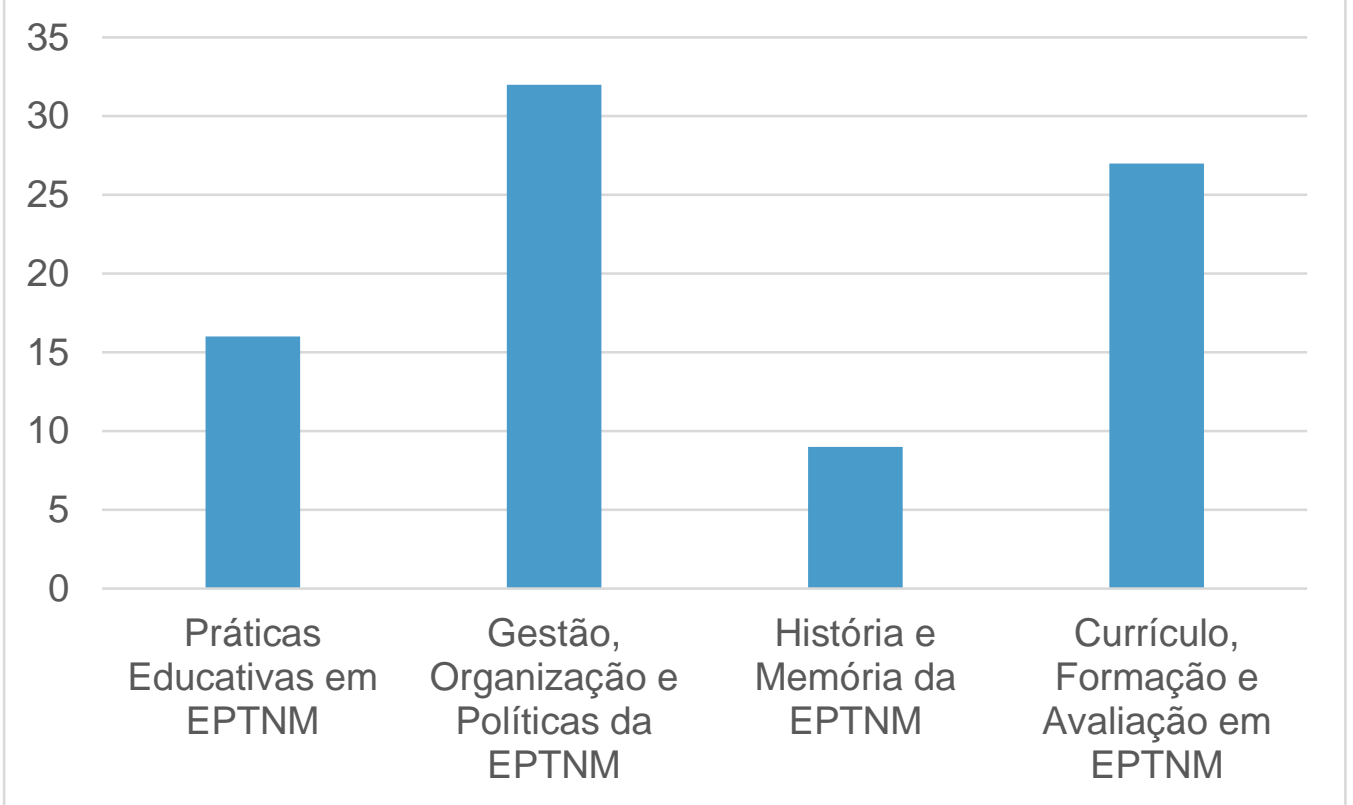

Fonte: os autores, a partir de dados da Dirac/IFPR (2020)

Nota-se que há um predomínio de TCC desenvolvidos na área de Gestão, Organização e Políticas da EPTNM, totalizando 32 trabalhos (38\% do total), e em uma análise mais criteriosa dos títulos, conclui-se que foram trabalhos que analisaram questões ligadas a prática diária dos pesquisadores, problemas com a organização do trabalho docente, políticas educacionais diversas ou gestão da informação. São exemplos desta linha:

- Turma 2014 - A influência da escola na integração das tecnologias educacionais: uma análise dos documentos institucionais do Instituto Federal do Paraná Campus Curitiba

- Turma 2015 - Políticas públicas de superação da evasão na Rede Federal de Educação Profissional e Tecnológica

- Turma 2017 - A reforma do ensino médio e os impactos na educação

Outra linha de destaque, com 27 TCC (32\% do total), é Currículo, Formação e Avaliação em EPTNM, com trabalhos representados em todas as turmas, englobando produções das mais diversas áreas de formação, desde o estudo de um componente curricular específico até possíveis mudanças na formação dos profissionais técnicos. São exemplos:

- Turma 2015 - A educação ambiental nos cursos técnicos integrados de Mecânica e Eletrônica do Instituto Federal do Paraná - Campus Curitiba

- Turma 2016 - Análise compreensiva da avaliação curricular na formação do aluno técnico em enfermagem: uma perspectiva da educação para o trabalho 
- Turma 2017 - Os arranjos produtivos e a formação profissional do técnico em telecomunicações no Instituto Federal do Paraná - Campus Curitiba

A terceira categoria com o maior quantitativo de TCC, 16 trabalhos representando 19\% do total, foi Práticas Educativas em EPT, que abarcou todas as produções que realizaram trabalhos empíricos em sala de aula, com práticas que possibilitaram mudanças no ensino e aprendizagem de cursos técnicos diversos. São exemplos destes TCC:

- Turma 2014 - O uso do Celular válido como Ferramenta Pedagógica em cursos técnicos profissionalizantes

- Turma 2016 - Fisioterapia e jogos digitais: desenvolvimento de um jogo para auxílio no tratamento Fisioterapêutico

- Turma 2017 - Utilização de aula prática contextualizada no processo de ensino aprendizagem de química na educação profissional

Por fim, porém não menos importante, destaca-se as pesquisas na área de História e Memórias da Educação Profissional Técnica de Nível Médio, pois mesmo com a menor quantidade de TCC ( 9 trabalhos, $11 \%$ do total), vale destacar que em todas turmas analisadas há produções nesta temática, como por exemplo:

- Turma 2014 - A história do Curso Técnico em Massoterapia do Instituto Federal do Paraná - Campus Curitiba

- Turma 2015 - Perseguição aos imigrantes alemães na Escola Alemã/Colégio Progresso

- Turma 2016 - História do curso de prótese dentária no IFPR - Campus Curitiba

Com isso, entende-se que a Especialização vem cumprindo seu papel enquanto curso de pós-graduação responsável pela formação e capacitação de professores especialistas para a educação profissional técnica de nível médio, pois pode-se averiguar pela análise dos TCC que todas as produções são relevantes, seja para a prática em sala de aula, para a gestão escolar, para as políticas educacionais ou mesmo para a reflexão sobre a história do curso em que se atua ou mesmo sobre as próprias práticas que o curso utiliza. Os benefícios do curso vão além do que a simples melhoria do processos diários, contribuindo para a formação de profissionais mais críticos, reflexivos, com caráter de pesquisadores e docentes prontos para atuarem em cursos técnicos e profissionalizantes.

\section{CONSIDERAÇÕES FINAIS}

Após análise dos primeiros seis anos de funcionamento da Especialização em Profissional Técnica de Nível Médio, pode-se afirmar que o 
IFPR tem cumprido seu papel na formação dos professores em nível de especialização. Ao todo foram mais de 80 (oitenta) estudantes certificados, sendo que uma grande parte destes atuam na educação profissional.

A análise dos TCC produzidos também corrobora com esta afirmação, e mesmo não tendo uma sincronicidade obrigatória no período de defesa dos TCC, ao analisar o conjunto dos trabalhos produzidos por uma turma, nota-se a influência, a evolução e a melhoria nas reflexões, na escrita e na formação dos estudantes que atuarão como professores na educação técnica e profissional.

Alguns dos professores atuantes no curso ingressaram posteriormente como docentes do ProfEPT (Programa de Pós-Graduação em Educação Profissiona e Tecnológica) do IFPR - Campus Curitiba. Por fim, destaca-se que o IFPR - Campus Curitiba oferta, além da Especialização em Educação Profissional Técnica de Nível Médio, mais 6 (seis) cursos: Especialização em Educação Musical para a Educação Básica; Especialização em Gestão Pública; Especialização em Gestão e Negócios; Especialização em Gestão Tributária, Contábil e Tributária; Especialização em Gestão Social em Políticas Públicas e, a recém aprovada, Especialização em Ensino de Ciências da Natureza (IFPR - CAMPUS CURITIBA, 2020). Todas as especializações ofertadas no IFPR são de caráter gratuito, afirmando um dos objetivos dos institutos federais que é a oferta de uma educação pública, gratuita e de qualidade.

\section{REFERÊNCIAS}

BRASIL. (2008). Lei n.. 11.892, de 29 de dezembro de 2008. Diário Oficial da União. 30. dez. 2008.

IFPR - CAMPUS CURITIBA. Instituto Federal do Paraná. Disponível em: <https://curitiba.ifpr.edu.br/menu-academico/nossos-cursos/pos-graduacao/>. Acesso em 01. Set. 2020.

IFPR - CAMPUS CURITIBA. Projeto Político Pedagógica da Especialização em Educação Profissional Técnica de Nível Médio. 2015. Disponível em: https://curitiba.ifpr.edu.br/wpcontent/uploads/2014/02/ESPECIALIZA\%c3\%87\%c3\%830EDUCA\%c3\%87\%c3\%830-PROFISSIONAL.pdf. Acesso em 01. Set. 2020.

IFPR - CAMPUS CURITIBA. Edital no 001/ 2014. Processo Seletivo para ingresso no Curso de Especialização em Educação Profissional - Lato Sensu no Câmpus Curitiba, 2014a. Disponível em: https://curitiba.ifpr.edu.br/wpcontent/uploads/2014/02/Edital-Pos-Graduacao-Educa\%c3\%a7\%c3\%a3oProfissional-revis-1.pdf. Acesso: 08. Set. 2020. 
IFPR - CAMPUS CURITIBA. Edital no 004/ 2014. Resultado do Processo Seletivo para ingresso no Curso de Especialização em Educação Profissional - Lato Sensu no Câmpus Curitiba, 2014b. Disponível em:

https://curitiba.ifpr.edu.br/wp-content/uploads/2014/03/Edital-Pos-GraduacaoEduca\%c3\%a7\%c3\%a3o-Profissional-04-2014-Resultadoprovis\%c3\%b3rio.pdf. Acesso: 08. Set. 2020.

IFPR - CAMPUS CURITIBA. Edital no 017/ 2014. Processo Seletivo para ingresso no Curso de Especialização em Educação Profissional - Lato Sensu no Câmpus Curitiba, 2014c. Disponível em: https://curitiba.ifpr.edu.br/wpcontent/uploads/2014/02/Edital-017-14-PROCESSO-SELETIVOespecializa\%c3\%a7\%c3\%a3o.pdf. Acesso: 08. Set. 2020.

IFPR - CAMPUS CURITIBA. Edital no 021/ 2014. Resultado do Processo Seletivo para ingresso no Curso de Especialização em Educação Profissional - Lato Sensu no Câmpus Curitiba, 2014d. Disponível em: https://curitiba.ifpr.edu.br/wp-content/uploads/2014/12/Edital-021-14PROCESSO-SELETIVO-especializa\%c3\%a7\%c3\%a3ohomologa\%c3\%a7\%c3\%a3o-das-inscri\%c3\%a7\%c3\%b5es-11.pdf. Acesso: 08. Set. 2020.

IFPR - CAMPUS CURITIBA. Edital no 45/ 2015. Resultado do Processo Seletivo para ingresso no Curso de Especialização em Educação Profissional - Lato Sensu no Câmpus Curitiba, 2015. Disponível em: https://curitiba.ifpr.edu.br/pos-graduacao/especializacao-em-educacaoprofissional/editais/. Acesso: 08. Set. 2020.

IFPR. Edital no 077/2016 - PROENS/IFPR. Processo seletivo simplificado para ingresso em curso de Pós-graduação Lato Sensu em Educação Profissional Técnica em Nível Médio do campus Curitiba, 2016a. Disponível em: https://curitiba.ifpr.edu.br/wp-content/uploads/2013/01/EDITAL-77-2016PROENS-IFPR.pdf. Acesso: 08. Set. 2020.

IFPR - CAMPUS CURITIBA. Edital ํo 025/2016. Homologação das inscrições, 2016b. Disponível em: https://curitiba.ifpr.edu.br/wpcontent/uploads/2014/02/Edital-025-16-PROCESSO-SELETIVO-P\%c3\%93SEDUCA\%c3\%87\%c3\%830-PROFISSIONAL-resultadohomologa\%c3\%a7\%c3\%a3o-das-inscri\%c3\%a7\%c3\%b5es.pdf. Acesso: 08. Set. 2020.

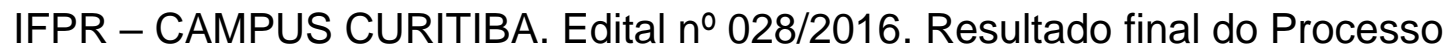
Seletivo para ingresso no curso de Especialização em Educação Profissional Técnica em Nível Médio, 2016c. Disponível em: https://curitiba.ifpr.edu.br/wpcontent/uploads/2014/02/Edital-028-16-PROCESSO-SELETIVO-P\%c3\%93SEDUCA\%C3\%87\%c3\%830-PROFISSIONAL-resultado-finalretifica\%c3\%a7\%c3\%a3o.pdf. Acesso: 08. Set. 2020.

IFPR - CAMPUS CURITIBA. EDITAL n0020/2017. Edital de Processo Seletivo Simplificado para preenchimento de até 30 vagas no Curso de 
Especialização Lato Sensu em Educação Profissional Técnica de Nível Médio do IFPR - Campus Curitiba, 2017a. Disponível em:

https://curitiba.ifpr.edu.br/wp-content/uploads/2017/06/Edital-020-17-

Processo-Seletivo-Especializa\%c3\%a7\%c3\%a3o-Educa\%c3\%a7\%c3\%a3o-

profissional.pdf. Acesso: 08. Set. 2020.

IFPR - CAMPUS CURITIBA. Homologação das inscrições do Processo Seletivo para ingresso no curso de Especialização em Educação Profissional Técnica de Nível Médio, 2017b. Disponível em: https://curitiba.ifpr.edu.br/wpcontent/uploads/2017/02/HOMOLOGAC\%cc\%a7A\%cc\%83O-DAS-

INSCRIC\%cc\%a70\%cc\%83ES-PO\%cc\%81S.pdf. Acesso: 08. Set. 2020.

IFPR - CAMPUS CURITIBA. Edital n 028/2017. Resultado final do Processo Seletivo em Especialização em Educação Profissional, 2017c. Disponível em: https://curitiba.ifpr.edu.br/wp-content/uploads/2017/11/Edital-028-17-

Processo-Seletivo-Especializa\%c3\%a7\%c3\%a3o-RESULTADO-FINAL.pdf. Acesso: 08. Set. 2020.

IFPR - CAMPUS CURITIBA. EDITAL n 31/2019 Edital de Processo Seletivo Simplificado para preenchimento de até 35 vagas no Curso de Especialização Lato Sensu em Educação Profissional Técnica de Nível Médio do IFPR Campus Curitiba, 2019a. Disponível em: https://curitiba.ifpr.edu.br/wpcontent/uploads/2019/05/Final-Vers\%c3\%a3o-4-maio-

EditalP\%c3\%b3sEduProfTECEM2019-2020.pdf. Acesso: 08. Set. 2020.

IFPR - CAMPUS CURITIBA. Candidatos aprovados no Processo seletivo para ingresso no curso de Especialização em Educação Profissional Técnica de Nível Médio referente ao Edital n 31/2019 do IFPR - CAMPUS CURITIBA, 2019b. Disponível em: https://curitiba.ifpr.edu.br/wpcontent/uploads/2019/06/Candidatos-aprovados-Espedu-2o-semestre-2019Edital-n\%c2\%ba-31 2019-\%e2\%80\%93-IFPR-\%e2\%80\%93-CAMPUSCURITIBA.pdf. Acesso: 08. Set. 2020.

IFPR - CAMPUS CURITIBA. Edital n³5/2019. Edital de Processo Seletivo Simplificado para preenchimento de até 15 vagas remanescentes no Curso de Especialização Lato Sensu em Educação Profissional Técnica de Nível Médio do IFPR - Campus Curitiba, 2019c. Disponível em: https://curitiba.ifpr.edu.br/wp-content/uploads/2019/07/Edital-35.2019-PSSEspecializa\%c3\%a7\%c3\%a3o-em-Educa\%c3\%a7\%c3\%a3o-Profissional1.pdf. Acesso: 08. Set. 2020.

MALDANER, J. J. A formação docente para a educação profissional e tecnológica: breve caracterização do debate. Revista Brasileira de Educação Profissional e Tecnológica. v. 2, n. 13, 2017.

MORURA, D. H. A formação de docentes para a educação professional e tecnológica. Revista Brasileira de Educação Profissional e Tecnológica. v. 1, n. 1, 2008. 
PACHECO, E. M. Os institutos federais: uma revolução na educação profissional e tecnológica. Natal: IFRN, 2010.

PACHECO, E. Fundamentos político-pedagógicos dos institutos federais: diretrizes para uma educação profissional e tecnológica transformadora. Natal: IFRN, 2015.

ORTIGARA, C.; GANZELI, P. (2013). Os Institutos Federais de Educação, Ciência e Tecnologia: permanências e mudanças. In: Batista, E. L.; Muller, M. T. (orgs). A educação profissional no Brasil: história, desafios e perspectivas para o Século XXI. Campinas: Editora Alínea. 